\title{
Nutritional and Therapeutic Importance of the Pumpkin Seeds
}

\author{
Qamar Abbas Syed*, Mafia Akram and Rizwan Shukat \\ National Institute of Food Science and Technology, Faculty of Food, Nutrition and Home Sciences, University of Agriculture \\ Faisalabad, Pakistan
}

*Corresponding author: Qamar Abbas Syed, Faculty of Food, Nutrition and Home Sciences, National Institute of Food Science and Technology, Pakistan

\begin{abstract}
ARTICLE INFO
Received: 幽 September 05, 2019

Published: 幽 September 12, 2019

Citation: Qamar Abbas Syed, Mafia Akram, Rizwan Shukat. Nutritional and Therapeutic Importance of the Pumpkin Seeds. Biomed J Sci \& Tech Res 21(2)2019. BJSTR. MS.ID.003586.
\end{abstract}

Keywords: Pumpkin Seeds; Nutrition; Therapeutic Properties

\begin{abstract}
The pumpkin seeds (Cucurbita sp.) from Cucurbitaceae family are usually considered as industrial waste products and thrown out. In some area's seeds are utilized as uncooked, cooked or roasted, although simply for the domestic purpose. As they are rich in protein, fibers, minerals like iron, zinc, calcium, magnesium, manganese, copper and sodium, PUFA (polyunsaturated fatty acids), phytosterol and vitamins, they might be considered important for the food industries. As the seeds are considered as byproduct of the pumpkin fruit, they are cheaper in cost and their utilization is different food products may lead to enhance their nutritional value at lower cost. Health promoting impacts of pumpkin seeds on the level of blood glucose, cholesterol, immunity, liver functioning, gallbladder, disabilities of leaning, prostate gland, depression, inflammation, cancer management and inhibition of parasites are established. The modification of these agroindustrial waste products into valuable elements is probably a huge footstep towards the direction of the universal efforts in food sustainability; hence, the further researches and studies should be planned to explore importance and beneficial effects of pumpkins and their seeds.
\end{abstract}

Abbreviations: PUFA: Polyunsaturated Fatty Acid; TIBC: Total Iron Binding Capacity; HPLC: High Performance Liquid Chromatography; GSH: Growth Stimulating Hormone; CAT: Chloramphenicol Acetyltransferase; MDA: Malondialdehyde and Antioxidant Enzyme

\section{Introduction}

Pumpkin (Cucurbita) belongs to the family Cucurbitaceae generally grown in the regions of the globe as a vegetable. These are grown-up in the tropical and sub-tropical regions and including the cucumbers and squash. Worldwide there are three types of the pumpkins are present name as "Cucurbita pepo", "Cucurbita maxima" and "Cucurbita moschata" Lee et al. [1]. For the purpose of vegetable and medicinal pumpkins are grown throughout world. In many countries the pumpkin has been conventionally used as remedy like China, Pakistan, India, Yugoslavia, Argentina, Mexican regions, America and Brazil Jia et al. [2,3]. The pumpkin seeds are utilized for the cure of different diseases the herbal remedies separately or combine with medicines are used for the medical treatment. The pumpkin is the one of the famous edible plant that is utilized as the cure of many disorders due to the occurrence of many edible components and phytochemicals Yadav et al. [4].
In USA, the pumpkins immensely used for the thanksgiving feats and cravings. The majority of the plant flora is processed into caned pumpkins. On the other hand, the considerable oval, flat shaped seeds are generally discarded as an agriculture residue. The pumpkin seeds are unique in flavored and nutty in taste and consumed salted and roasted as a snack in few regions of Mexico, Canada, United States, China and Europe. Now a days, these pumpkin seeds are selling as fermented, sprouted, baked, concentrated form of protein from pumpkins and pumpkin protein isolate, as the pumpkin seeds are rich in iron, protein, manganese, magnesium, zinc, potassium, copper, phosphorous, PUFA (polyunsaturated fatty acid), c-tocopherol and carotenoids. There is an emergent interest in unique formation of vegetable oil, and oil of the pumpkin seeds is a hopeful aspirant on this regard. Steam distillation or Cold press is done for oil extraction. The dark greenish red colored pumpkin 
seed oil is used for cooking, marinade and dressing of salad. It is being utilized in many chocolates, epicurean delight, cereal bars, bread, cakes, soups, pesto, muffin, pasta garnish and garnish of stew. The butter of pumpkin seeds is taken into consideration as a marvelous peanut butter alternative.

The many food shops of United State such as Walmart, Costco and Trader Joe, promote numerous food products primarily based on pumpkin seeds, like vegetable salad, granola chunks, breads, quinoa salad, tortilla chips and cookies. The Australia, Serbia, Hungary and Slovenia produced the maximum pumpkin seeds oil. The fame of the pumpkin seeds and pumpkin seeds oil is increasing day by day in many countries in the world that is a gathering momentum slowly but surely Patel [5]. The importance of utilization of pumpkin seeds and iron fortified ready to eat cereal as two dietary iron sources was studied and check the iron nutritional status of women at reproductive age. The 8 healthy women, nonpregnant or unmarried, 20-37 years old provide them ready to eat cereal 30 gram and pumpkin seeds 30 gram for 4 weeks. The blood Specimens were collected on 20 day of menstruation period before and after utilization of seeds and cereal and hematological index such as $\mathrm{Hb}, \mathrm{Fe}$, Hematocrit, Ferritin, TIBC (Total iron binding capacity) and transferrin were found. The response for iron level was better after consumption period. The results indicated that other sources of iron can improve iron status such as pumpkin seeds Naghii et al. [6].

\section{Nutritional Importance}

The physical properties, chemical composition and fatty acid proportion was determined by an investigator and his collogues they found that pumpkin seeds contained $41.59 \%$ oil, $25.4 \%$ protein, $5.2 \%$ Moisture, 25.19\% carbohydrates, 5.34\% fiber, and $2.49 \%$ total ash. Total phenolic compounds, total sterols, waxes and total tocopherols were 66.25 (mg galic acid per $\mathrm{kg}$ oil), 1.86\%, $1.56 \%$ and 882.65 (mg tocopherol per kg oil) respectively Ardabili [7].

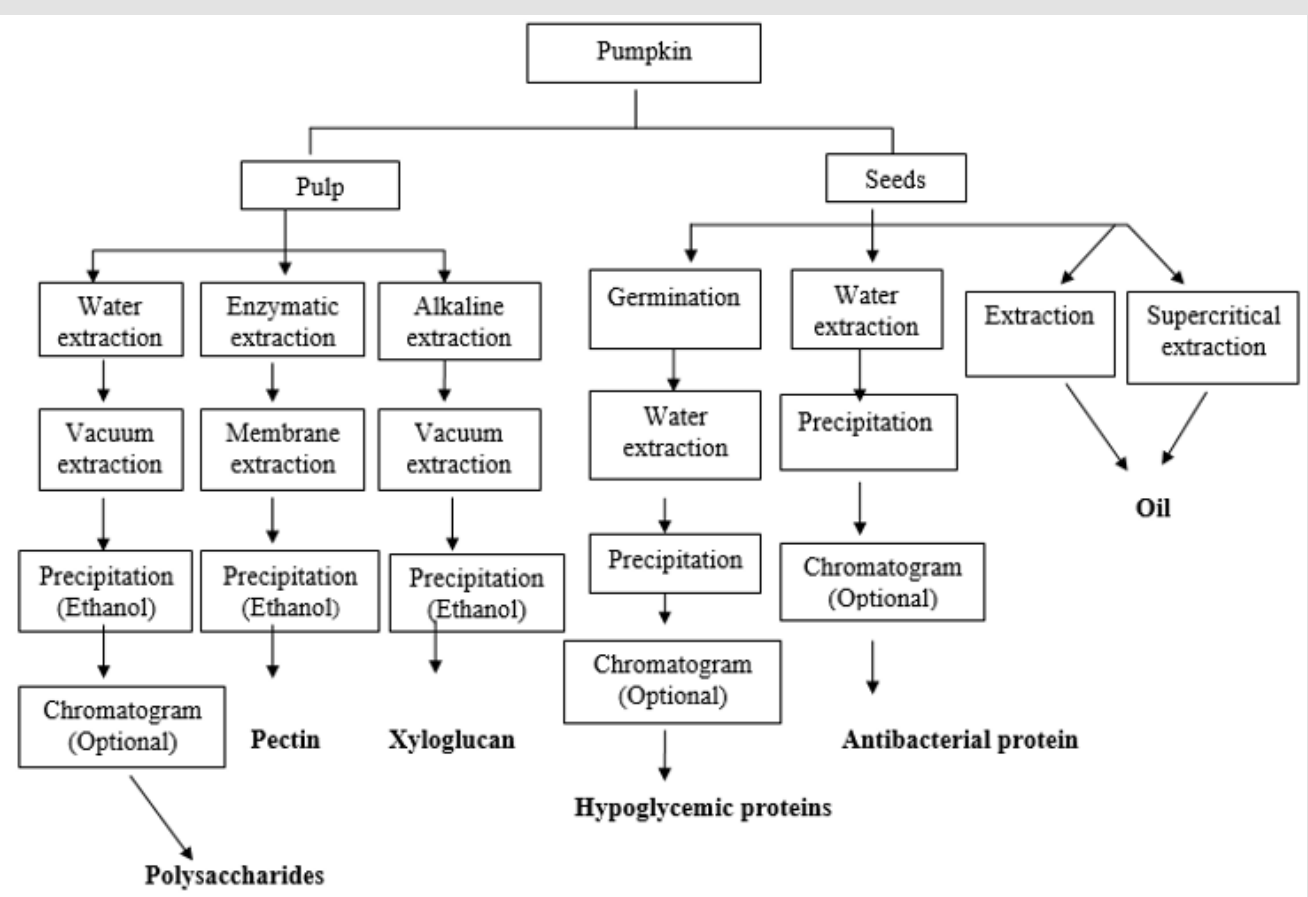

Figure 1: Extraction of bioactive components from pumpkin seeds and pulp.

Table 1: Nutritional Values of Pumpkin seeds per 100g.

\begin{tabular}{|c|c|c|}
\hline Components & Nutritional Values & RDA Percentage \\
\hline Carbohydrates & 10.71 grams & 28 Percent \\
\hline Energy & $559 \mathrm{Kcal}$ & 164 Percent \\
\hline Total Fats & $49.05 \mathrm{~g}$ & 54 Percent \\
\hline Protein & $30.23 \mathrm{~g}$ & 16 Percent \\
\hline Fiber & $6 \mathrm{~g}$ & 0 Percent \\
\hline Cholesterol & $0 \mathrm{mg}$ & 15 Percent \\
\hline Micronutrients (Vitamins) & & 31.0 Percent \\
\hline $\mathrm{B}_{9}$ (Folic acid) & 58 micro gram \\
\hline $\mathrm{B}_{3}($ Niacin) & $4.8 \mathrm{mg}$ & 15.0 Percent \\
\hline $\mathrm{B}_{5}$ & $0.75 \mathrm{mg}$ & \\
\hline
\end{tabular}




\begin{tabular}{|c|c|c|}
\hline $\mathrm{B}_{6}$ & $0.14 \mathrm{mg}$ & 11.0 Percent \\
\hline $\mathrm{B}_{2}$ & $0.15 \mathrm{mg}$ & 12 Percent \\
\hline $\mathrm{B}_{1}$ (Thiamin) & $0.272 \mathrm{mg}$ & 23 Percent \\
\hline Vit. C & $0.272 \mathrm{mg}$ & 3.0 Percent \\
\hline Vit. A & $16 \mathrm{IU}$ & 0.50 Percent \\
\hline Vit. E & $35.1 \mathrm{mg}$ & 272 Percent \\
\hline \multicolumn{3}{|l|}{ Major Minerals } \\
\hline $\mathrm{Na}^{+}$ & $7.0 \mathrm{mg}$ & 0.5 Percent \\
\hline $\mathrm{K}^{+}$ & $809.0 \mathrm{mg}$ & 17.0 Percent \\
\hline \multicolumn{3}{|l|}{ Mineral Deposits } \\
\hline $\mathrm{C}^{+}$ & $46.0 \mathrm{mg}$ & $41 / 2$ Percent \\
\hline $\mathrm{Cu}$ & $1.43 \mathrm{mg}$ & 148.0 Percent \\
\hline Fe (Iron) & $8.8 \mathrm{mg}$ & 110.0 Percent \\
\hline $\mathrm{Mg}$ & $592 \mathrm{mg}$ & 148 Percent \\
\hline $\mathrm{Mn}$ & $4.54 \mathrm{mg}$ & 195 Percent \\
\hline $\mathrm{P}$ & $1232 \mathrm{mg}$ & 175 Percent \\
\hline Se & 9.40 micro gram & 17.0 Percent \\
\hline $\mathrm{Zn}$ & $7.8 \mathrm{mg}$ & 17.0 Percent \\
\hline \multicolumn{3}{|l|}{ Phytochemicals } \\
\hline Beta-Carotenoid & 9 micro gram & --- \\
\hline Beta-Crypto Xanthin & 1 micro gram & --- \\
\hline Lutein-Zeaxanthin & 74 micro gram & --- \\
\hline
\end{tabular}

Researchers investigated in pumpkin seeds the phytosterol, tocopherol and squalene levels. The approach consists of acid hydrolysis and extraction by lipids observed through the means of alkaline saponification before the analysis by the means of HPLC (High performance liquid chromatography). The beta-sitosterol becomes the maximum standard phytosterol, ranging from $24.90 \mathrm{mg}$ per 100 gram of pumpkin seeds (Table 1 ). The squalene turned into specially consideration (89mg per 100 gram) and the complete contents of oil material amount to 42.30 percent in seeds of pumpkins Ryan et al. [8]. Kim and colleagues mentioned that the fatty acids (FAs.) within the seeds of pumpkins have been Palmitic acid, oleic acid, linoleic acids and Stearic acid. The Cucurbita moschata and Cucurbita pepo seeds had notably much more c-tocopherol than Cucurbita maxima, whose seeds had the more b-carotene. Seeds of Cucurbita pepo had notably more b-sitosterol than the pumpkin types. Among 11 varieties of seeds and nuts profile for dietary abundance, for iron content scored highest the pumpkin seeds (95.85 \pm 33.01 ppm) Kim et al. [9]. Major bioactive components in parts of pumpkin i.e. from seeds and pulp are summarized in below flow diagram and the major processes of extraction of the bioactive components (Figure 1).

\section{Antioxidant Activity}

The total phenolic contents of pumpkin seed oil were determined by some investigators that were ranged between 25 to $51 \mathrm{mg} / \mathrm{kg}$ of pumpkin seed oil. The phenolic contents were vanillin, tyrosol, luteolin, sinapic acid and vanillic acid. There was the max antioxidant capacity calculated with the aid of the reduction of the DPPH radical was 62 percent Andjelkovic et al. [10]. Nkosi and colleagues studied the antioxidative role of isolated protein of pumpkin seed on rats kept on a low-protein weight-reduction feed plan for five days. The isolated pumpkin seed protein was given to rats that have been subjected to intoxication of acetaminophen. At the 24, 48 and 72 hours after their particular treatment the rats were killed. The protein isolated from pumpkin seeds showed about $80 \%$ radical scavenging activity, chelating activity was round about $64 \%$ on $\mathrm{Fe}^{2+}$ ions and xanthine oxidase inhibition were approximately $10 \%$. The CCl4-triggered damage of liver and goes into increased by using pumpkin protein isolated as evidenced from the decreased level of lipid per oxidation the increased antioxidant level Nkosi et al. [11].

An investigator stated that oil of pumpkin seed protects in rats, the small bowel from destruction induced by methotrexate through anti-inflammatory and anti-oxidative activities. Oral administration of the oil along with ellagic acid or pumpkin seed oil separately for five days earlier to treatment by methotrexate decrease the damage of small intestine, serum myelo peroxidase, prostaglandin, tissue nitric oxide, malondialdehyde, xanthine oxidase and adenosine deaminase stimulate and increase level of GSH (growth stimulating hormone) and its storage El-Boghdady [12]. Ward and Ainsworth produced the less expensive weaning meals with good enough energy from diet, protein and fat in Kenya for infants that are malnourished. The porridge was cooked, dried and then add pumpkin seeds powder in it and followed by heat treatment then stored at ambient temperature for the duration of 2 months. A meal of high-quality protein is confirmed by the protein 
digestibility measured that was $82.50 \%$. By the HPLC analysis the food stability was indicated and there were no free water-soluble amino acids were detected. The absence of rancidity is confirmed by the low peroxide value and viscosity of porridge is measured by viscometer Ward et al. [13].

\section{Therapeutic Impotence}

There are many research studies that have been proving the health benefits and protective effects of the pumpkin and its parts like pumpkin seeds, pulp and their extractions (bioactive components).

\section{Hypolipidaemic Effects}

Makni and his colleagues evaluated by the animal model based experimental study (rats), the role pumpkin seed and flax seed mixture by providing cholesterol diet $1 \%$. After completed the study they observed the considerable boost in monounsaturated fatty acid (MUFA) and polyunsaturated (PUFA) levels in seeds fed group. The anti-atherogenic activity of the pumpkin and flex seeds mixture was indicated by the level of bolstered antioxidant defense system and level of malondialdehyde Makni et al. [14].

Some researchers studied the role of supplementation of oil of pumpkin seeds on the total, and low-density lipoprotein cholesterol, cholesterol and high-density lipoprotein cholesterol, systolic and diastolic B.P (blood pressure) in rats both non-ovariectomized and ovariectomized rats that were fed with the oil of pumpkin seeds and oil of corns 5 days in a week for the total duration of 12 weeks (40mg supplementation/ $\mathrm{kg}$ by mouth). The evaluation of blood samples confirmed high levels of healthy lipid in the group fed with supplement of oil of pumpkin seeds Gossell-Williams et al. [15]. The two investigators tested the effects of pumpkin seeds in high cholesterol fed rat through pumpkin seeds in combination with the flex seeds or purslane seeds. The administration of the $2 \%$ cholesterol diet cause increase in total cholesterol, triglyceride and total lipid in both in liver and serum. The utilization of pumpkin seeds and flax seeds or pumpkin seeds and purslane seeds blend cause reduction in lipid and suggested as these seed's combinations have anti-atherogenic activity Barakat et al. [16].

\section{Antimicrobial Effects}

The major cause of deaths of many people is the bacteria, parasites, viruses and fungi that develop many diseases and lead to death despites of the hygienic environment and foods. The pumpkin seed oil contains the components that are antimicrobial components and have been isolated from oil of pumpkin seeds. The oil of pumpkin seeds at the concentration of the $2 \%$ inhibit the growth of Aeromonas veronii, Candida albicans, Enterociccus feacalis, Escherichia coli, Salmonella enterica, Typhimurium, and Staphylococcus aureus Hammer et al. [17].

The basic protein of pumpkin seeds MAP2, MAP11 and MAP4 had been explored to stop the yeast cell's growth. Among all basic proteins the MAP11 showed the more inhibitory effects than other proteins. The MAP2 and MAP4 did not inhibit the growth of the G-ve (gram negative) bacteria Escherichia coli Cheong et al. [18]. Moreover, it has been reported that from pumpkin seeds the phloem exudates having the anti-fungal properties and inhibit the pathogenic fungus Xie [19]. Park and his colleagues isolated the new protein known as pr-1 protein form pumpkin seeds that have antifungal potential with no toxicity in human erythrocytes (RBCs). It is the heat stable protein and stable at $70^{\circ} \mathrm{C}$ temperature without growth inhibiting activity towards E. Coli and Staphylococcus bacteria Park et al. [20].

\section{Hypertensive and Heart Protective Effects}

The pumpkin seeds have essential role in blood pressure lowering and relaxing of blood vessels. It have been examined the role and effects of pumpkin seeds oil in rats that have high blood pressure induced by chemical. The oil served on daily basis for 6 weeks the oil range between 40 to $100 \mathrm{mg}$ per Kg. Consumption of the oil appreciably decreased elevated blood pressure resulting from the induction by chemical and electrocardiogram changes also became normal. It also maintains the decreased level of NO metabolites to normal range and increased MDA level to decrease. The overall outcome confirmed the protective effect of pumpkin seed oil towards pathological changes in the aorta and coronary heart. The NO production is indicated the amino acid L-arginine. Additionally, the high magnesium (mg) content in pumpkin seeds oil is credited to lessening the risks of coronary heart attack. The pumpkin seeds as dietary supplement has exposed the same effects to the calcium channel blocker as a drug amlodipine El-Mosallamy et al. [21].

\section{Anti-Carcinogenic Effects}

The rapidly prevailing health problem is the cancer. There is a biggest challenge for the investigators, professionals and researchers to select preventive and therapeutical strategies to prevent and cure the cancer. There are many fruits and vegetables have been found to minimize the risk factor of the cancer. The diet having high amount of pumpkin seeds have been identified as lowering the cancer risks. The pumpkin seeds oil has been found to reduce the risks of cancer as it contained the high amount of the various carotenoid's pigments Jian et al. [22]. The Gossell William and colleagues determine the role of oil of pumpkin seeds in chemical (testosterone) induced hyperplasia rats. The rats were feed with pumpkin seeds oil and corn oil during the hyperplasia induction for the duration of twenty days. At the $21^{\text {st }}$ day the prostate was weight after killed and analyzed. They were found that the increased prostate growth inhibition occurred in rats that were served with oil of pumpkin seeds (2mg per $100 \mathrm{~g}$ ). The protecting effects of the oil of pumpkin seeds were more considerable at high dose. The result of research study develops the hope for cancer management Gossell William et al. [23].

Hong and colleagues have been conducted a double-blinded placebo-control randomized trial on hyperplasia patients. The task 
continued for 3 month they observed that symptoms and signs of the cancer have been decreased and also improved overall quality of life of the people Hong et al. [24]. There was a food frequency questionnaire developed and group of women vulnerable to cancer was fed with pumpkin seeds and sunflower seeds. At the end of the period of consumption and study it was concluded that the pumpkin seeds and sunflower seeds are associated with significantly postmenopausal risks of breast cancer Zaineddin et al. [25].

\section{Anti-Diabetic Effects}

The diabetes mellitus is the one of the most prevailing affecting all aged people. The diabetes mellitus is the disorder of metabolic system in which the body does not construct the enough in insulin or insulin produce but body do not repose properly to insulin. Type I diabetes and Type II diabetes are the two main types of the diabetes. There are many researches that stated that pumpkin seeds and pumpkin contained the components that lower the blood glucose level. Many diabetic people avoid the pumpkin use because of high carbohydrate content while there is no $\mathrm{d}$ threat from pumpkin consumption. It has been determined that the hypoglycemic and antioxidant effects of pumpkin seeds and flax seeds combination in diabetic rats. The characteristics of histopathological alterations have CAT(Chloramphenicol acetyltransferase), GSH(Growth stimulating hormone) and SOD (superoxide dismutase) and decreased MDA (malondialdehyde and antioxidant enzyme). The increases in glucose, overall lipid, triglycerides and overall cholesterol in plasma were substantially unresponsive Makni et al. [26]. It has been determined that oil of pumpkin seeds food regimen decrease the elevated level of the enzymes alanine aminotransferase (ALT) in plasma and aspartate aminotransferase that reverse the risks of diabetes occurrence. It is consumed in normal food may be useful for the diabetes prevention and the complications of diabetes Makni et al. [27].

It has been determined the hypoglycemic effects of protein isolated from different types of pumpkin seeds from the family of Cucurbitaceae including Cucurbita moschata. The outcome of the oral glucose tolerance take a glance at completed on rats discovered that globulin become the most ample storage protein which calculated 295 milligram per gram dry matter calculated and proficient of cause significantly decrease in sugar level in blood (88 to $137.80 \%$ ) Teugwa et al. [28].

\section{Pumpkin Seeds Effects on Axalcrystallurea}

It is investigated that the effect of supplementation of pumpkin seeds on urinary composition axalcrystallurea in 20 children (boys) age 2-7 years from a hyper-endemic in Thailand region of Ubol province. The experimental research study had 4 time periods: manage (previous to cure), supplementation of oxalate 5 milligram per kilogram of body weight every day, supplementation of pumpkin seed 60 milligram per kilogram of body weight every day and after treatment every morning 24 hour urines have been obtain and analyzed for crystallurea, calcium, phosphorus, creatinine, $\mathrm{pH}$, oxalate, citrate glycosaminoglycans, sodium, potassium and pyrophosphate. The effects tested that the pumpkin seeds supplementation period longer, the outcomes will be the better. The seeds of Pumpkin decrease the formation crystal of calciumoxalate and calcium level; however, enhance glycosaminoglycans, phosphorus, potassium and pyrophosphate values in urine in comparison with supplementation of orthophosphate. The seeds of Pumpkin provide excessive phosphorus quantity and can be used as an effective content in minimizing the threat of stone in bladder Voranunt et al. [29-32].

\section{Conclusion}

The above research studies confirmed that the pumpkin seeds have nutritional and therapeutic properties as well as these are also served as delicious food in many regions of the globe. The pumpkin seeds are cultivated in tropical and subtropical areas. There are three main types are cultivated such as Cucurbita pepo, Cucurbita maxima and Cucurbita moschata. The nutrient composition analysis of pumpkin seeds showed that these are very nutritious and provide many essential nutrients for health. However, the pumpkin seeds have been used for medicinal purpose and these possess also nutritional and therapeutic importance. The pumpkin seeds play a significant role in providing of micronutrients and also used in treatment and management of diabetes, inflammation, hyperlipidaemia, hypertension, cancer management and protect heart etc. (Kalogropoulos, 2013). In Pakistan the pumpkin seeds are used for the cultivation and thrown out as a waste. There should be further studies and awareness about their nutritional and therapeutic value so that people make these a part of their daily meal.

\section{References}

1. Lee YK, WI Chung, H Ezura (2003) Efficient Plant Regeneration via Organogenesis in Winter Squash (Cucurbita maxima Duch). Plant Sciences 164 (3): 413-418.

2. Jia W, W Gao, L Tang (2003) Antidiabetic herbal drugs officially approved in China. Phytotherapy Research 17(10): 1127-1134.

3. Adolfo AC, H Michael (2005) Mexican plants with hypoglycemic effect used in the treatment of diabetes. Journal of Ethnopharmacology 99: 325-348.

4. Yadav M, S Jain, R Tomar, GBKS Prasad, H Yadav (2010) Medicinal and biological potential of pumpkin. Nutrition Research Review 23(2): 184190 .

5. Seema Patel (2013) Pumpkin (Cucurbita sp) seeds as nutraceutic: a review on status quo and Scopes. Mediterranean Journal of Nutrition Metabolism 6(3): 183-189.

6. Naghii MR, M Mofid (2007) Impact of daily consumption of iron fortified ready-to-eat cereal and pumpkin seed kernels (Cucurbita pepo) on serum iron in adult women. Biofactors 30(1): 19-26.

7. Ardabili, AG, R Farhoosh, M HH Khodaparast (2011) Chemical Composition and Physicochemical Properties of Pumpkin Seeds (Cucurbita pepo Subsp pepo Var Styriaka) Grown in Iran. Journal of Agriculture Sciences and Technology 13: 1053-1063.

8. Ryan E, K Galvin, TP Connor, AR Maguire, NM Brien (2007) Phytosterol, squalene, tocopherol content and fatty acid profile of selected seeds, 
grains, and legumes. Plant Foods and Human Nutrition 62(3): 85-91.

9. Kim MY, EJ Kim, YN Kim, C Choi, BH Lee (2012) Comparison of the chemical compositions and nutritive values of various pumpkin (Cucurbitaceae) species and parts. Nutrition Research Practices 6(1): 21-27.

10. Andjelkovic M, J Van Camp, A Trawka, R Verhe (2010) Phenolic compounds and some parameters of pumpkin seed oil. Euorpian Journal of Lipid Science 112(2): 208-217.

11. Nkosi CZ, AR Opoku, SE Terblanche (2006) Antioxidative effects of pumpkin seed (Cucurbita pepo) protein isolate in CCl4- induced liver injury in low-protein fed rats. Journal of Phytotherapy Research 20(11): 935-940.

12. El Boghdady NA (2011) Protective effect of ellagic acid and pumpkin seed oil against methotrexate-induced small intestine damage in rats. Indian Journal of Biochemistry and Biophysiology 48(6): 380-387.

13. Ward D, P Ainsworth (1998) The development of a nutritious low cost weaning food for Kenya infants. African Journal of Health Sciences 5(12): $89-95$.

14. Makni M, H Fetoui, NK Gargouri, M Garoui, H Jaber, et al. (2008) Hypolipidemic and hepatoprotective effects of flax and pumpkin seed mixture rich in omega-3 and omega- 6 fatty acids in hypercholesterolemic rats. Food Chemistry Toxicology 46(12): 3714-3720.

15. Gossell Williams M, C Hyde, T Hunter, D Simms Stewart, H Fletcher, et al. (2011) Improvement in HDL cholesterol in postmenopausal women supplemented with pumpkin seed oil: pilot study. Climacteric 14(5): 558-564.

16. Barakat LA, RH Mahmoud (2011) The anti-atherogenic, renal protective and immunomodulatory effects of purslane, pumpkin and flax seeds on hypercholesterolemic rats. North American Journal of Medical Sciences 3(9): 411-417.

17. Hammer KA, CF Carson, TV Riley (1999) Antimicrobial activity of essential oils and other plant extracts. Journal of Applied Microbiology 86(6): 985-990.

18. Cheong NE, YO Choi, WY Kim, Bae IS, Cho MJ, et al. (1997) Purification and characterization of an antifungal PR-5 protein from pumpkin leaves. Journal of Molecular Cell 7(2): 214-219.

19. Xie JM (2004) Induced polarization effect of pumpkin protein on B16 cell. Fujian Medical University Acta 38: 394-395.

20. Park SC, JR Lee, JY Kim, Hwang I, Nah JW, et al.(2010) Pr-1, a novel antifungal protein from pumpkin rinds. Biotechnology Letters 32(1): 125-130.

\section{ISSN: 2574-1241}

DOI: 10.26717/BJSTR.2019.21.003586

Qamar Abbas Syed. Biomed J Sci \& Tech Res

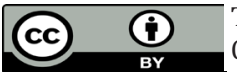

This work is licensed under Creative

Commons Attribution 4.0 License

Submission Link: https://biomedres.us/submit-manuscript.php
21. El Mosallamy AE, AA Sleem, OM Abdel Salam, N Shaffie, SA Kenawy (2012) Antihypertensive and cardioprotective effects of pumpkin seed oil. Journal of Medicinal Food 15(2): 180-189.

22. Jian L, CJ Du, AH Lee, Binns CW (2005) Do dietary lycopene and other carotenoids protect against prostate cancer. International Journal of Cancer 113(6): 1010-1014.

23. Gossell Williams M, A Davis, N O'Connor (2006) Inhibition of testosterone-induced hyperplasia of the prostate of Sprague- Dawley rats by pumpkin seed oil. Journal of Medicinal Food 9(2): 284-286.

24.Hong H, CS Kim, S Maeng (2009) Effects of pumpkin seed and saw palmetto oil in Korean men with symptomatic benign prostatic hyperplasia. Nutrition Research Practices 3(4): 323-327.

25. Zaineddin AK, K Buck, A Vrieling, J Heinz, D Flesch Janys, et al. (2012) The association between dietary lignans, phytoestrogen-rich foods, and fiber intake and postmenopausal breast cancer risk: a German casecontrol study. Nutrition and Cancer-journal 64(5): 652-665.

26. Makni M, M Sefi, H Fetoui, M El Garoui, NK Garouri, et al. (2010) Flax and pumpkin seeds mixture ameliorates diabetic nephropathy in rats. Food Chemistry and Toxicology 48(8-9): 2407-2412.

27. Makni M, H Fetoui, NK Gargouri, M El Garoui, N Zeghal (2011) Antidiabetic effect of flax and pumpkin seed mixture powder: effect on hyperlipidemia and antioxidant status in alloxan diabetic rats. Journal of Diabetes Complications 25(5): 339-345.

28. Teugwa CM, T Boudjeko, BT Tchinda, PC Majiato, D Zofou (2013) Antihyperglycaemic globulins from selected Cucurbitaceae seeds used as antidiabetic medicinal plants in Africa BMC Complementry and Alternative Medicine 13: 63.

29. Voranunt SS, C Yarnnon, P Ngunboonsri (1987) The effects of pumpkin seeds on oxaicrystafluria and urinary compositions of children in hyperendemic area. American Journal of Clinical Nutrition 45(1): 115121.

30. Chung KH, KO Shin, HJ Hwang, KS Choi (2013) Chemical composition of nuts and seeds sold in Korea. Journal of Nutrition Research Practices $7(2): 82-88$

31. Kalogeropoulos N, A Chiou, MS Ioannou, VT Karathanos (2013) Nutritional evaluation and health promoting activities of nuts and seeds cultivated in Greece. International Journal of Food Science and Nutrition 64(6): 757-767

32. Zhou T, Q Kong, J Huang, R Dai, Q Li (2007) Characterization of Nutritional Components and Utilization of Pumpkin. Global Science Books 1: 313321.

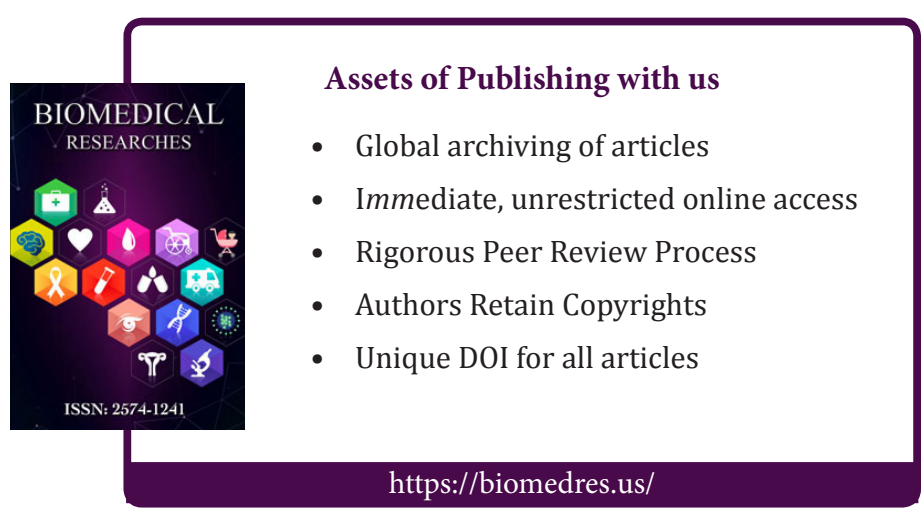

